\title{
BENTANG LAHAN JAWA BAGIAN TENGAH Sebuah Catatan Lapangan di Propinsi Daerah Istimewa Yogyakarta
}

\author{
Inayah Hidayati \\ Pusat Penelitian Kependudukan LIPI
}

\begin{abstract}
Abstrak: Bentang lahan mencakup bentang alami dan bentang budaya yang menekankan keterkaitan antara komponen biogeofisik dengan manusia dan segala aktivitasnya. Objek yang dikaji dalam tulisan ini terdiri dari dua kelompok besar yaitu geografi dan geografi sosial. Metode yang digunakan dalam tulisan ini adalah pengamatan lapangan dengan menyusuri jalur perjalanan yang telah ditentukan, melakukan pengamatan, identifikasi, dan pengukuran setiap parameter pada setiap fenomena penyusun bentang lahan. Kondisi bentang lahan Jawa bagian tengah sisi selatan didominasi oleh batuan batugamping di bagian atas dan dialasi oleh batuan vulkanik tersier, berupa breksi dan aliran lava yang muncul di tepi laut. Kondisi ini mengakibatkan potensi sumber daya alam terbatas sehingga berpengaruh terhadap penghidupan penduduknya. Kemudian wilayah tengah hingga Gunung Merapi dari Provinsi Daerah Istimewa Yogyakarta merupakan zona tengah relatif lebih sempit dari bagian yang lain. Morfologi zona ini terbentuk oleh pegunungan Serayu selatan dan utara serta kompleks gunungapi. Zona ini relatif lebih subur dan memiliki sumber daya alam yang melimpah. Hasil pengamatan di lapangan menegaskan bahwa terbentuknya bentang alam tidak bisa terlepas dari unsur alam dan aktivitas manusia yang saling mempengaruhi satu sama lain.
\end{abstract}

Kata kunci : bentang lahan, Jawa bagian tengah, morfologi, penghidupan masyarakat

Abstract: Landscapes include natural landscapes and cultural landscapes that emphasize the relationship between the biogeophysical components and humans and all their activities. The objects studied in this paper consist of two major groups, namely geography and social geography. The method used in this paper is field observations by following a predetermined travel path, observing, identifying and measuring each parameter in each of the landscape constituent phenomena. The landscape of Java in the central part of the south side is dominated by limestone rocks at the top and covered by tertiary volcanic rocks, in the form of breccias and lava flows that appear on the edge of the sea. This condition results in limited natural resource potential which affects the livelihoods of its inhabitants. Then the central area to Mount Merapi from the Yogyakarta Special Region Province is the middle zone which is relatively narrower than the other parts. The morphology of this zone is formed by the mountains of southern and northern Serayu and the volcanic complex. This zone is relatively more fertile and has abundant natural resources. The results of observations in the field confirm that the formation of landscapes cannot be separated from natural elements and human activities that influence one another.

Keywords: landscape, central Java, morphology, community livelihoods 


\section{A. PENDAHULUAN}

Bentang lahan mencakup bentang alami (natural landscape) dan bentang budaya (cultural landscape) yang menekankan keterkaitan antara komponen biogeofisik dengan manusia di dalamnya dan segala aktivitasnya untuk memenuhi kebutuhan hidup (Conzen, 2001). Pendekatan yang digunakan untuk mengetahui hubungan keterkaitan tersebut merupakan ciri kajian geografi yaitu pendekatan keruangan (spatial approach), kelingkungan (ecological approach), dan kompleks wilayah (regional approach) (Forman, 2014; Turner, 1989; Chorley dan Kennedy, 1971). Untuk mempelajari bentang lahan perlu dikenalkan komponen biogeofisik dan sebarannya di lapangan beserta pemetaannya, hubungan antara biogeofisik, dan hubungan antara komponen biogeofisik dengan manusia.

Menurut Tuttle (1975), bentang lahan merupakan gabungan dari bentukan lahan atau landform dan kombinasi dari kenampakan tersebut akan membentuk suatu bentang lahan. Berdasarkan definisi tersebut maka dapat dimengerti bahwa unit analisis yang sesuai adalah unit bentuklahan. Maka untuk menganalisis dan mengklasifikasi bentang lahan harus selalu berdasar pada kerangka kerja bentuklahan (landform). Bentuklahan adalah bagian dari permukaan bumi yang mempunyai bentuk topografi yang khas dan unik yang disebabkan oleh proses alam dan geologi pada material batuan dalam skala ruang dan waktu kronologis tertentu (Verstappen, 2011). Verstappen (1983) mengklasifikasikan bentuk lahan menjadi 10 macam berdasarkan asal prosesnya yaitu: vulkanik, struktural, fluvial, solusional, denudasional, eolian, marine, glasial, organik dan antropogenik.

Kemudian bentang budaya merupakan kenampakan dari suatu masyarakat yang mempunyai pengertian sebagai sekumpulan penduduk dengan seluruh karakteristik sosialnya dan lingkungan sosialnya yang meliputi faktor-faktor kebiasaan, tradisi, adat istiadat, hukum, kepercayaan, agama, ideologi, dan sebagainya (Mitchell, 2002). Bentang budaya timbul sebagai hasil interaksi dan adaptasi antara manusia dengan alam dan dalam prosesnya terjadi hubungan timbal balik. Dari hubungan tersebut maka akan membentuk suatu perwujudan bentang budaya dengan jenis tertentu dan tentunya juga akan mengakibatkan munculnya gejala sosial seperti kemiskinan, kepadatan penduduk, jenis mata pencaharian, dan sebagainya. Untuk mengklasifikasikan bentang budaya maka dapat dilakukan dengan menggunakan pendekatan lokasi (site \& 
situational) yaitu dibagi menjadi dua yaitu bentang desa dan kota yang mempunyai kenampakan budaya, sosial, ekonomi, dan fisik yang berbeda-beda (Rowntree, 1996).

Melalui interpretasi dan analisis peta, foto udara, atau citra penginderaan jauh yang didukung dengan data dan observasi lapangan maka akan diperoleh karakteristik dari masing-masing komponen bentang lahan baik komponen fisik maupun komponen sosial ekonomi dan budayanya. Analisis komponen bentang alam pada umumnya didasarkan atas relief, struktur, dan proses yang dinamakan bentuk lahan (landform). Bentuk lahan digunakan sebagai satuan analisis yang menggunakan pendekatan keruangan, kelingkungan, dan kompleks wilayah yang selanjutnya dapat digunakan untuk menentukan kebijakan dalam perencanaan pemanfaatan lahan baik dalam skala lokal, regional, maupun nasional. Komponen bentang budaya dapat dikenali dengan mudah mendasarkan pada aktivitas manusia dalam memanfaatkan lahan yang tercermin pada pemanfaatan ruang seperti yang dapat terlihat pada bentang pertanian, industri, pemukiman, dan sebagainya. Selain itu secara garis besar bentang budaya juga dapat dikelompokkan menjadi bentang desa dan kota yang masing-masing mempunyai karakteristik yang khas.
Kajian bentuklahan sebagai dasar analisis dan kerangka umum dalam kajian bentang lahan pengelompokannya berdasarkan pada proses utama yang meliputi bentukan asal vulkanis, struktural, fluvial, solusional, denudasional, eolian, marin, organik, dan antropogenik. Aspek bentang budaya Jawa bagian tengah juga memiliki karakteristik yang kompleks pula yaitu meliputi bentang desa dan bentang kota yang memiliki karakteristik sosial dan ekonomi serta budaya yang khas dan spesifik seperti bentang pertanian, perikanan, hutan, industri, dan perdagangan.

\section{B. METODE}

Pendekatan yang digunakan dalam penelitian ini adalah adalah pendekatan deskriptif. Metode yang digunakan dalam tulisan ini adalah pengamatan lapangan dengan menyusuri jalur perjalanan yang telah ditentukan, melakukan pengamatan, identifikasi, dan pengukuran setiap parameter pada setiap fenomena penyusun bentang lahan. Lokasi penelitian di Provinsi Daerah Istimewa yang mewakili jenis bentuk lahan. Hasil observasi diharapkan dapat menggambarkan objek dan fenomena yang ada. 


\section{HASIL PENELITIAN}

\section{C.1. Pembentukan Pulau Jawa}

Pulau Jawa merupakan bagian dari Lempeng Tektonik Pasifik, dimana berada pada jalur pertemuan lempeng Indo-Australia dengan Pasifik (Bemmelen, 1949; Wessel \& Kroenke, 2000; Verstappen, 2000). Gerakan lempeng di Indonesia pada umumnya adalah saling bertemu, yaitu lempeng benua dan samudra saling bertumbukan yang ditandai dengan penunjaman ke bawah dimana lempeng samudera dengan massa berat yang lebih besar menunjam lempeng benua, yang menunjam adalah massa penyusun material daratan (Strahler, 1987; Irwon, 1990; Hall, 2009). Akibat penunjaman tersebut menyebabkan terbentuknya palung dan terjadi formasi batuan yang tidak selaras sehingga terjadi pergerakan yang mempengaruhi magma dalam bumi. Pada saat penunjaman, semakin ke bawah suhu semakin tinggi, sehingga tekanan tinggi. Pada kedalaman tertentu penunjaman tersebut dapat menghancurkan litosfer dan menguraikan astenosfer sehingga menyebabkan jalur dalam bersifat vulkanik (Thouret, 1999; Kurnianto, 2019). Pergerakan lempeng tektonik tersebut membentuk kepulauan di Indonesia, termasuk Pulau Jawa yang terjadi gaya endogen pengangkatan dan dapat memunculkan busur-busur gunung api (Verstappen, 2000).

Menurut klasifikasi Bemmelen (1970), Provinsi Daerah Istimewa Yogyakarta masuk dalam wilayah Jawa bagian tengah secara penampang geologisnya. Bagian tengah wilayah ini merupakan depresi dan muncul kelompok gunung api. Jenis endapan di wilayah ini adalah vulkanik muda. Kemudian semakin ke selatan berupa plato, berlereng (miring) ke arah selatan menuju Laut Hindia dan di sebelah utara berbentuk tebing patahan. Kadang zona ini begitu terkikis sehingga kehilangan bentuk platonya. Di Jawa tengah bagian dari zona ini telah ditempati oleh dataran aluvial.

Di zona selatan ini lapisan yang lebih tua terdiri dari endapan vulkanis yang tebal (breksi tua) dan bahan-bahan endapan (seperti tanah anulatus) yang terlipat pada waktu periode miosen tengah (Pannekoek, 1949; Nossin \& Voute, 1986). Di bagian selatan zona ini sedikit mengalami lipatan tetapi lipatan ini menjadi lebih kuat dekat batas sebelah utara. Daerah ini merupakan daerah peralihan ke zona tengah. Bagian ini ditutupi secara tidak selaras (unconform) oleh bahan-bahan yang tidak terlepas dari miosen atas (Nossin \& Voute, 1986). 


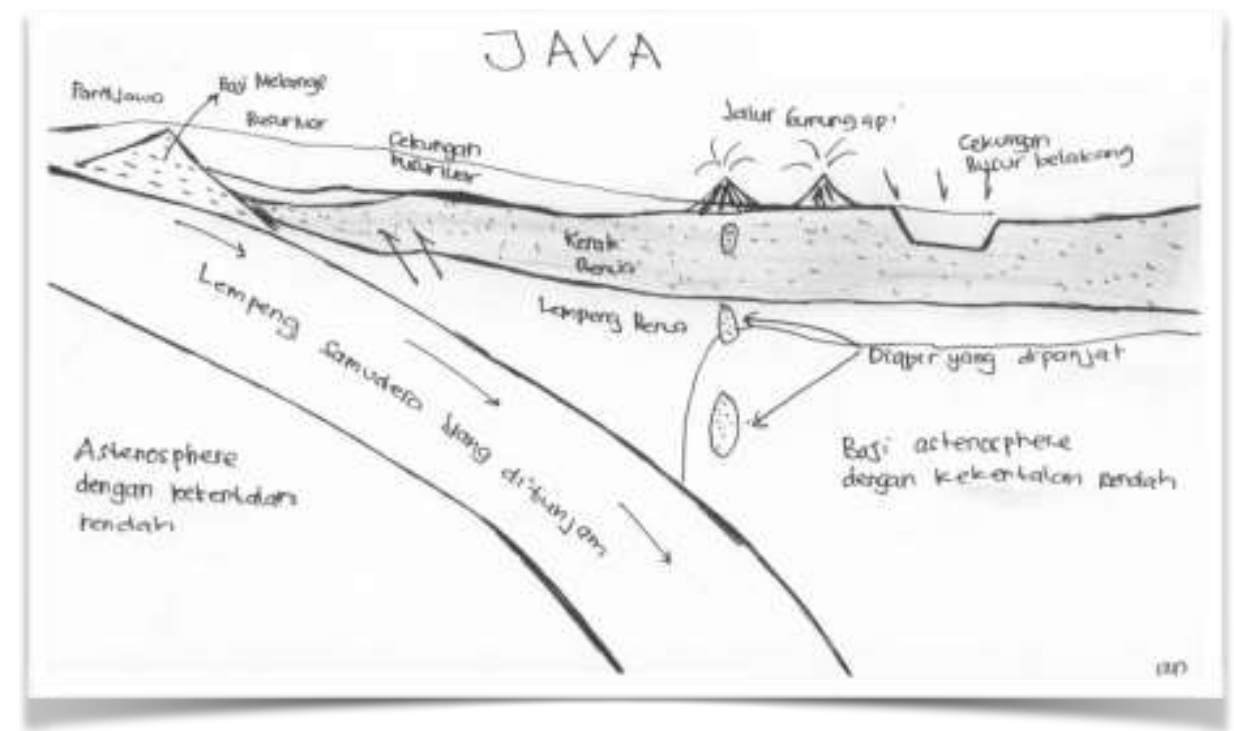

Gambar 2. Pembentukan Pulau Jawa (Ilustrasi oleh Hidayati, 2004 \& 2018)

\section{C.2. Kondisi Bentang Lahan Lokasi}

\section{Penelitian}

Untuk memahami bentang lahan digunakan batasa satuan geologis dan fisiografisnya. Secara garis besar kondisi geomorfologi Provinsi Daerah Istimewa Yogyakarta dibagi menjadi empat kelompok besar dengan kekhasan fisik dan sosial kemasyarakatannya yaitu:

\section{Satuan Gunung Merapi}

Merupakan bentang lahan vulkanik yang terdiri dari kerucut gunung api hingga dataran fluvial gunung api yang tersebar di Sleman, Kota Yogyakarta hingga sebagian daerah Bantul. Bentang lahan ini terbentuk sebagai akibat dari letusan Gunung Merapi. Gunung Merapi tumbuh pada titik potong antara kelurusan vulkanik Ungaran - Telomoyo - Merbabu - Merapi dan kelurusan vulkanik Lawu - Merapi Sumbing - Sindoro - Slamet (Suyanto, 2012).
Kelurusan vulkanik Ungaran Merapi tersebut merupakan sesar mendatar yang berbentuk konkaf hingga sampai ke barat, dan berangsur-angsur berkembang kegiatan vulkanisnya sepanjang sesar mendatar dari arah utara ke selatan (Santosa, 2006). Dapat diurut dari utara yaitu Ungaran yang berumur Pleistosen dan berakhir di selatan yaitu Gunung Merapi yang sangat aktif hingga saat ini. Kadang disebutkan bahwa Gunung Merapi terletak pada perpotongan dua sesar kuarter yaitu Sesar Semarang yang berorientasi utara-selatan dan Sesar Single yang berorientasi barattimur (Santosa, 2006; Hartini \& Sartohadi, 2010).

Secara morfologi tubuh gunung Merapi dapat dibagi menjadi empat bagian yaitu Kerucut Puncak, Lereng Tengah dan Lereng Kaki dan Dataran Kaki (Santosa, 2006; Hartini \& Sartohadi, 2010). Kerucut puncak 
dibangun oleh endapan paling muda berupa washes dan piroklastik. Satuan lereng tengah dibangun oleh endapan washes, piroklastik dan lahar. Lereng kaki dan Dataran Kaki tersusun dari endapan piroklastik, lahar dan aluvial. Dari bentuknya, dibandingkan dengan gunung api di sebelahnya yaitu Gunung Merbabu, Gunung Merapi nampak jauh lebih runcing. Hal ini menunjukkan bahwa pertumbuhan bagian puncaknya relatif lebih cepat.

Hal ini didukung pula oleh kenyataan bahwa pada saat ini produk aktivitas Merapi hanya tersebar pada jarak yang dekat dari puncak Merapi. Kerucut puncak Merapi yang sering disebut sebagai Gunung Anyar merupakan bagian Merapi yang paling muda (Islamiyah, Minarto \& Santoso, 2019; Hardjono, 2015; Wismaya, 2016). Semua aktivitas Merapi terpusat pada puncak kerucut ini. Kawah utama Merapi saat ini berupa bukaan berbentuk tapal kuda yang mengarah ke barat-barat daya. Morfologi kawah ini terbentuk sesudah letusan tahun 1961 (Tjia, 1961; Thouret, Lavigne \& Bronto, 2000). Secara umum, dataran puncak Merapi tersusun dari kubah-kubah washes yang tidak longsor.
Beberapa area dataran puncak Merapi di luar kawah utama mengeluarkan banyak uap vulkanik yaitu di area Gendol dan Woro, bagian tenggara dataran puncak. Bagian lereng barat Merapi merupakan daerah aliran guguran dan piroklastik (Islamiyah, Minarto \& Santoso, 2019; Hardjono, 2015; Voight, Constantine, Siswowidjoyo \& Torley, 2000). Daerah ini merupakan daerah terbuka karena sering dilanda awan panas. Daerah lereng timur sebagai bagian dari struktur Merapi jarang terkena dampak aktivitas Merapi. Lereng ini lebih banyak tertutup dengan vegetasi. Morfologinya nampak dipisahkan dari kerucut-Merapi dengan sesar yang berbentuk tapal kuda yang melalui bawah Gunung ljo (Islamiyah, Minarto \& Santoso, 2019).

Lereng kaki Merapi tersusun dari punggung-punggung radial yang diselingi dengan hulu-hulu sungai. Beberapa sungai penting yang berada di lereng barat yaitu Batang, Bebeng, Putih, Blongkeng, Sat, Lamat dan Senowo. Alur-alur pada hulu sungai tersebut yang sering mendapat tambahan material produk letusan (Bourdier, \& Abdurachman, 2001). 


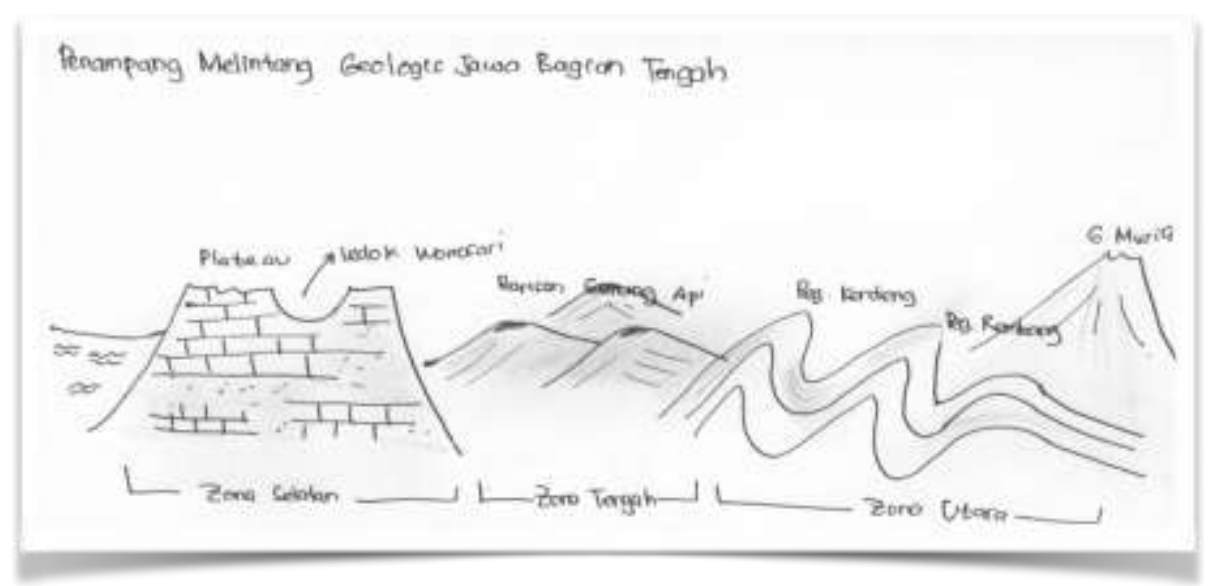

Gambar 3. Penampang Melintang Geologis Jawa Bagian Tengah

(Ilustrasi oleh Hidayati, 2004 \& 2018)

Gunung Merapi merupakan gunung api tipe basalt-andesitik dengan komposisi $\mathrm{SiO}_{2}$ berkisar antara 50-58 \% (Sarkowi, 2010). Beberapa washes yang bersifat lebih basa mempunyai $\mathrm{SiO}_{2}$ yang lebih rendah sampai sekitar 48\%. Batuan Merapi tersusun dari plagioklas, olivin, piroksen, magnetit dan amphibole Setiahadiwibowo, Nugroho \& Pratama, 2020). Plagioklas merupakan mineral utama pada batuan Merapi dengan komposisi sekitar 34\% (Sarkowi, 2010).

Oleh karena aktivitasnya yang terus-menerus, Merapi merupakan sumber bahan galian pasir, kerikil dan batu yang tidak ada habisnya. Aktivitas tersebut juga merupakan ciri khas Merapi yang lain daripada gunungapi. Tanpa mengurangi kewaspadaan akan adanya resiko bahaya, suatu letusan merupakan setoran material baru bagi eksploitasi bahan galian pasir dan batu. Diantara produk letusan, endapan awan panas merupakan produk yang bernilai ekonomis. Dieksploitasi dalam selang beberapa minggu setelah suhunya mendingin endapan tersebut dapat dimanfaatkan.

Dari sudut pengembangan wisata, aktivitas Merapi terutama pada saat terjadi aliran-aliran washes pijar merupakan pemandangan yang khas. Awan Panas memang merupakan kejadian yang sangat berbahaya untuk daerah-daerah atau alur-alur yang terancam. Namun demikian tetap ada lokasi-lokasi aman untuk menikmati dan melihat proses aktivitas Merapi. Pada malam hari aliran awan panas dan washes pijar akan nampak membara dan menjadi daya tarik sendiri bagi orang yang tinggal jauh dari gunung api atau di dekat suatu gunung api yang tidak pernah meletus. Bagi pelajar, pemantauan proses letusan secara langsung memberikan contoh riil dari proses alam yang terjadi di bumi. Dari sudut pandang ini kejadian letusan dan proses aktivitas vulkanik of 
Merapi dapat ditawarkan sebagai suatu obyek kunjungan semi ilmiah.

Di penghujung bagian tengah satuan Gunung Merapi terdapat Graben Bantul yang memiliki karakteristik khas sebagai daerah yang terbentuk oleh sesar yang melintang ke utara di sisi timur Parangtritis hingga Prambanan dan sisi barat pada arah utara selatan Palbapang yang merupakan sisi timur perbukitan Sentolo di daerah Bantul. Jika dilihat dari ketinggian maka akan terlihat secara jelas bahwa Graben Bantul diapit oleh dua formasi yaitu formasi Sentolo dan formasi Wonosari.

Menurut proses geomorfologinya, pembentukan Graben Bantul sangat erat kaitannya dengan aktivitas Gunungapi Merapi. Terutama pada pengisian sedimen pembentuk Graben Bantul. Dilihat rangkaiannya dengan keberadaan Gunungapi Merapi Graben Bantul merupakan bagian dari fluvio vulkanik plain dari Merapi yang mempunyai ciri datarannya sudah rata dan tanahnya memiliki perlapisan (Daryono, 2012).

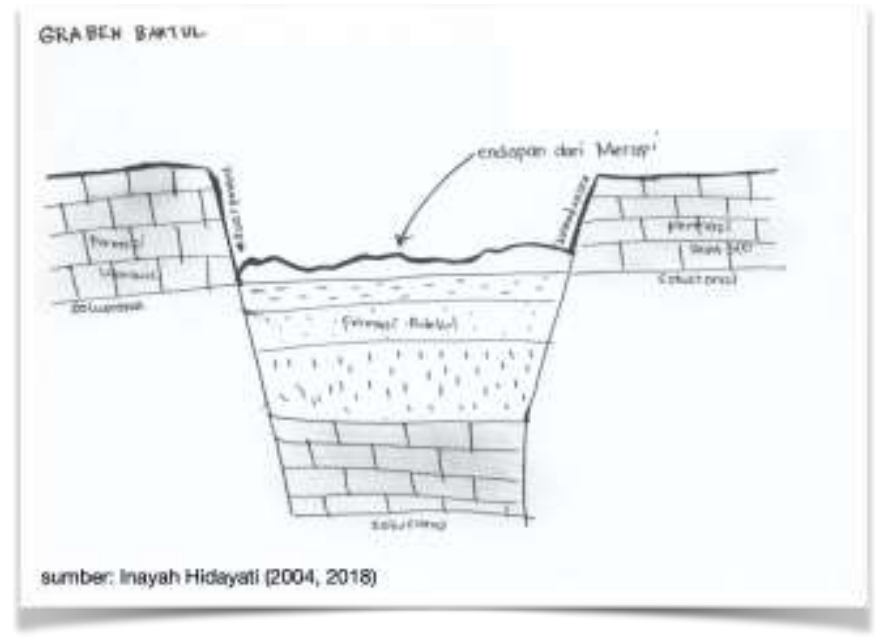

Gambar 3. Pembentukan Graben Bantul

(Ilustrasi oleh Hidayati, 2004 \& 2018)

Hasil pengamatan menunjukkan jenis tanah yang ada di Bantul merupakan jenis tanah aluvial yang mempunyai ciri bertekstur lempung berpasir yang halus dengan warna lapisan tanah bagian atasnya lebih gelap daripada lapisan yang ada di bawahnya dan keberadaan air yang menggenang dan dangkal serta infiltrasinya kecil sehingga sangat cocok untuk lahan pertanian basah atau persawahan (Rudiyanto, 2012). Selain itu tanah di Bantul juga mempunyai horison-horison tanah yaitu horison A (elevasi / tanah asal), horison B (iluviasi /karena proses pencucian dan akumulasi), dan horison $\mathrm{C}$ (pelapukan dan akumulasi) (Rayes, 2017).

Selain itu memasuki wilayah Bantul juga bisa mulai dirasakan perubahan ekspresi topografi yang 
semakin ke arah selatan akan semakin melandai. Melandainya ekspresi topografi tersebut disebabkan karena terjadinya proses sortasi atau pemilihan ukuran butiran batuan atau tanah dari yang semula kasar yang berasal dari material Merapi menjadi semakin halus yang disebabkan karena tenaga yang membawa batuan tersebut menjadi semakin lemah pada daerah landai dari yang semula kuat pada daerah lereng miring.

Berdasarkan bentang budayanya, kawasan selatan Provinsi Daerah Istimewa Yogyakarta ini merupakan daerah kompleks yang mempunyai ciri perkotaan dan pada sebagian wilayah lainnya masih bercirikan pedesaan. Namun secara umum, di Bantul bisa dilihat dan dirasakan atmosfer perubahan pola wilayah dari yang bercirikan pedesaan menjadi perkotaan menurut penggunaan lahannya.

Perubahan tersebut mulai bisa diamati dari daerah Bantul yang berbatasan dengan kota Yogyakarta yang penggunaan lahannya masih bercirikan perkotaan dan bersifat heterogen yang dalam artiannya masih banyak sekali ditemui lahan yang digunakan sebagai pemukiman, perkantoran, maupun sarana kegiatan perekonomian dan mulai memasuki Jalan Bantul mulai dirasakan transformasi daerah perkotaan menjadi daerah pedesaan dengan homogennya penggunaan lahan yaitu digunakan sebagai daerah pertanian terutama persawahan.

Namun karena perkembangan, pertumbuhan, dan kepadatan penduduk semakin hari semakin meningkat, maka pada daerah Bantul terutama yang berbatasan dengan kota Yogyakarta menjadi urban sprawl dari dinamika Kota Yogyakarta. Hal ini dapat dilihat dari perkembangan pembangunan perumahan di wilayah Bantul dan perpindahan fasilitas pendukung kota seperti universitas, pusat kegiatan ekonomi, dan sebagainya dari pusat kota ke daerah pinggiran. Fenomena urban sprawl ini akan menyebabkan harga tanah yang ada di Bantul semakin melonjak tinggi dan memicu terjadinya land use change berbagai bentang lahan yang ada. Apalagi di daerah Bantul jika dilihat dari segi aksesibilitas, daya dukung lingkungan, dan fasilitas pendukung lainnya termasuk cukup lengkap sehingga akan menarik pertumbuhan urban ke arah rural.

Kemudian di penghujung selatan yang berbatasan dengan lautan terdapat bentuk lahan pantai yang memiliki ciri bergumuk pasir baik yang aktif maupun yang tidak aktif dan adanya pantai berbatu dengan tebing yang terjal atau bisa disebut cliff. Terbentuknya Gumuk Pasir di Pantai Parangtritis sangat erat kaitannya dengan aktivitas Gunungapi Merapi (Nurkholis, Jayanto \& Jurnawan, 2018; Dibyosaputro \& Haryono, 2020). 
Saat Merapi meletus maka Merapi mengeluarkan piroklastis yang berupa bom, pasir, lapili, debu, dan sebagainya. Materi yang berupa pasir dan lapili setelah diangkut sungai hanya akan mengendap di lereng Gunungapi Merapi. Sedangkan pasir yang berukuran lebih besar diangkut oleh sungai Opak dan Progo hingga ke laut dan setelah masuk ke laut oleh longshore current atau arus susur saat musim kemarau diangkut dan disebarkan di sekitar pantai dan oleh gelombang pasir tersebut dihempaskan ke darat (Dibyosaputro \& Haryono, 2020). Pertemuan arus datang dan arus balik menyebabkan terjadinya beting gisik yang mempunyai ledok diantaranya. Setelah itu maka terjadilah endapan pasir di pantai (membentuk daratan). Saat ada angin muson tenggara yang terpengaruh Pegunungan Sewu ke arah hinterland, angin sedikit berbelok ke arah barat dan dipercepat sehingga kemampuan angin untuk mengangkut pasir menjadi lebih besar dan semakin ke barat kemampuannya semakin berkurang yang menyebabkan gumuk pasir di Pantai Parangtritis lebih tinggi dibanding dengan sebelah baratnya (Verstappen, 1988). Endapan yang dijatuhkan oleh angin tersebut akan membentuk suatu gundukan pasir atau populernya disebut gumuk pasir (Verstappen, 1957).

Adapun syarat pembentukan gumuk pasir adalah jika ada banyak suplai material berukuran pasir, termasuk daerah yang terbuka dari penghalang (vegetasi ), ada perbedaan musim yang tegas, dan angin yang kuat. Gumuk pasir menurut sifatnya dibagi menjadi dua yaitu gumuk pasir aktif dan gumuk pasir yang tidak aktif. Gumuk pasir tidak aktif adalah gumuk pasir yang telah ditumbuhi vegetasi sehingga ada penghalang bagi angin untuk merubah bentuk pasir yang ada. Sedangkan gumuk pasir yang aktif adalah gumuk pasir yang tidak bervegetasi dan permukaan pasirnya terjamah angin sehingga setiap saat bentuknya selalu berubah-ubah. Gumuk pasir yang aktif ini sangat dipengaruhi oleh aktivitas proses eolian. Jenis gumuk pasir yang aktif dapat dibedakan menjadi tiga macam yaitu gumuk pasir normal yaitu gumuk pasir yang berbentuk bukit kecil-kecil sekitar 5 hingga 20 meter dengan kemiringan yang terjal sekitar $15^{0}$, gumuk pasir longitudinal yang bentuknya memanjang searah arah angin, dan gumuk pasir barchan yang pola penyebarannya berpola jarang-jarang dan bentuknya seperti wiru atau yang disebut dengan ripple mark (Verstappen, 1957; Maulana \& Wulan, 2015; Santosa, 2016). Punggung yang ada di barchan ini bentuknya selalu berubah-ubah karena pengaruh angin. Uniknya, pola gumuk pasir barchan ini hanya akan ditemui di Parangtritis. Pasir yang dapat ditemui di daerah Parangtritis adalah pasir yang berwarna hitam. Warna ini terjadi karena material pasir yang berat dan pada 
umumnya berwarna hitam tertinggal di pantai dan material yang berwarna lebih terang dan ringan terbawa angin dan terbang ke daerah hinterland.

Daratan sekitar pantai Parangtritis karena dulunya merupakan daerah yang terpengaruhi aktivitas fluvial Sungai Opak maka datarannya relatif subur dan cocok untuk daerah pertanian (Wardhana, 2015). Dataran yang ada di sini dahulunya merupakan bekas laguna yang mengalami deposisional sehingga membentuk dataran yang tinggi. Sedangkan bekas backswamp yang ada di sekitar daerah pantai Depok-Parangtritis banyak yang dimanfaatkan sebagai lahan pertanian. Sedangkan permukiman penduduk banyak ditemui di tanggul sungai.

Menurut tata ruangnya daerah ini merupakan pantai berpasir yang sangat cocok dikembangkan menjadi daerah wisata karena keunikannya. Namun di daerah ini juga mengalami permasalahan yang cukup pelik, yaitu pada daerah sempadan pantainya. Karena termasuk daerah wisata maka pembangunan semakin menuju ke arah daerah sempadan pantai. Padahal daerah sempadan pantai seharusnya dibiarkan terbebas dari pembangunan agar dapat melindungi pantai. Daerah sempadan pantai diukur berdasarkan pasang tertinggi dan terendahnya.

Gejala sosial ekonomi di Pantai Parangtritis adalah banyak penduduknya yang bermata pencaharian rangkap, yaitu mereka mengerjakan pertanian terpadu yang berdasarkan keadaan alamnya dan merangkap sebagai nelayan saat keadaan alam tidak memungkinkan untuk melakukan kegiatan pertanian dan saat itu kegiatan perikanan sangat menjanjikan hasil. Namun sebagai nelayan, penduduk juga mendapatkan tantangan yang sangat besar dari alam. Yaitu kendala gelombang dan arus laut yang sangat besar sehingga sangat menyulitkan nelayan untuk melaut dan mendarat. Di daerah laut ada pembagian zona penangkapan ikan yang bertujuan melindungi nasib nelayan kecil. Zonanya adalah: daerah sempadan pantai, jalur penangkapan $1 \mathrm{~A} \quad(1-2) \quad$ yang diperuntukkan bagi nelayan tradisional, dan zone 1B (3-4) yang diperuntukkan bagi nelayan dengan peralatan modern. Selain masalah dalam perikanan, masyarakat pesisir juga mengalami kesulitan pada masalah pertanian yaitu dengan masalah sulitnya sumber air dan pola drainase yang tidak tertata. Pola permukiman di pesisir ini mayoritas berpola memanjang searah dengan pantai.

Pada sisi bagian barat Pegunungan Sewu terjadi sesar bertingkat dan di bagian selatannya terbentuk cliff yang bagian bawahnya mengalami abrasi yang berakibat batuan yang diatasnya akan berguguran dan menumpuk di pelataran laut (Marfai, Cahyadi \& Anggraini, 
2013; Setyawan, Apriyanto \& Astutik, 2019). Pelataran ini akan timbul tenggelam sesuai dengan pasang surut air laut. Pada pelataran ini sering sekali terjadi dan terbentuk alur yang sangat berbahaya karena bisa terjadi arus balik yang berkecepatan tinggi yang banyak menelan korban jiwa. Kondisi yang demikian itu juga terjadi pada garis pantai yang cekung. Pada garis pantai ini arus balik menjadi sangat cepat karena terjadi konsentrasi arus balik atau yang disebut dengan rip current (Retnowati, Marfai, \& Sumantyo, 2012). Pada pantai yang berpasir, letak rip current berpindah-pindah

(Deskaranti, Prasetyawan \& Kunarso, K. 2017). Rip current dapat dikenali dari morfologi pantai yang cekung dan gelombangnya tidak pecah (Retnowati, 2012). Rip current ini termasuk arus yang sangat mematikan karena yang sudah terbawa oleh arus ini kemungkinan untuk selamat sangat rendah.

Di daerah Nambangan, perbatasan Bantul dan Gunung Kidul, terdapat penampakan perbatasan yang terlihat tegas antara zona satuan Gunung Merapi dengan Pegunungan Selatan. Pembatas zona ini ditandai dengan adanya escarpment atau gawir, intrusi diorit, dan bentuk perbukitan yang kompleks seperti patahan (lihat gambar 5). Pengangkatan bagian selatan Jawa, menyebabkan terjadinya sesar memanjang dan melintang Jawa. Sesar memanjang mengangkat bagian selatan Jawa, sedangkan sebagian lagi tidak terangkat, sehingga terbentuk Plato Selatan (Santosa, 2016). Sesar melintang menyebabkan tidak semua bagian selatan Jawa membentuk plato, namun ada sebagian yang tenggelam dan sekarang tertutup oleh endapan, fluvial, marin dan eolin, membentuk daratan (Verstappen, 2000). Sesar yang terjadi pada Plato Selatan ternyata bukan hanya yang melintang Jawa, namun masih banyak sesar sekunder dengan arah sejajar membentuk sesar tangga atau memotong Perbukitan Baturagung. Dengan terbentuknya plato ini maka terbentuk pula gawir atau escarpment, dan dalam perkembangan selanjutnya dapat terbentuk trapezoidal facet, triangle facet, lembah menggantung, kerucut aluvial dan kipas aluvial (Strahler, 1987; Irwon, 1990; Hall, 2009)..

Pada kipas aluvial ini tanah lembab dan lebih subur, dan kemungkinan terdapat mata air atau rembesan, sehingga vegetasi lebih rapat dan banyak digunakan untuk lahan pertanian atau pemukiman penduduk. Munculnya air di wilayah ini secara hidrologi adalah karena saat air hujan turun maka akan ada singkapan batuan yang mengalir kebawah dan mengerosi. Dari proses tersebut maka akan terbentuk suatu lembah yang mengandung banyak air dengan bentuk memanjang (garis) dan vegetasi penutupnya rimbun. Kemudian 
air yang mengalir ke bawah tersebut muncul di celah kecil dengan kecepatan besar di daerah fluvio vulkanik fan. Pada daerah fluvio vulkanik fan tersebut banyak bermunculan air dari tanah dan mengakibatkan daerah ini subur dan kaya air sehingga cocok untuk dikembangkan menjadi daerah pertanian lahan basah.

\section{Gambar 5. Triangle Facet, Kipas Aluvial, Escarpment, dan Meandering Sungai Opak (Ilustrasi oleh Hidayati, 2004 \& 2018)}

Pada dataran terbentuk dataran aluvial dengan materi berasal dari Merapi terletak di sebelah utara sungai dan dataran visual yang terletak di sebelah selatan sungai dengan materi berasal dari Perbukitan Baturagung. Batuan pada dataran aluvial Merapi tersusun oleh geluh, pasir dan kerikil, sedangkan batuan pada dataran aluvial Baturagung tersusun oleh lempung sebagai hasil pelapukan vulkanik Tersier dan batugamping (Muryowihardjo, 1988; Sarkowi, 2010; Hidayat dkk, 2013; Mulyasari, Brahmantyo \& Supartoyo, 2020). Oleh karena itu maka sifat dan watak kedua dataran aluvial sangat berbeda. Dataran aluvial Merapi bertekstur pasir, tidak mengalami kembang kerut, sedangkan dataran aluvial Baturagung bertekstur lempung mengalami kembang kerut. Di daerah ini juga terdapat batuan vulkanik beku (breksi) seperti yang ada di Parang Kusumo dan masih merupakan satu rangkaian.

Dari segi sosial budayanya, di wilayah Nambangan ini hanya cocok untuk dikembangkan jenis tanaman tahunan dan jenis tanaman musiman tidaklah cocok untuk dikembangkan di sini. Karena daerahnya sudah mulai beralih menjadi perbukitan patahan, maka dalam penggunaan lahannya pun mulai dilakukan penyesuaian. Lahan yang ada di lereng atas dan topografinya kasar dan berteras-teras cenderung 
dimanfaatkan untuk penanaman tanaman tegalan. Sedangkan pada daerah bagian bawah yang topografinya halus dan banyak mengandung air karena berada pada fluvio vulkanik fan di kembangkan pertanian lahan basah atau persawahan.

Untuk pola pemukimannya, di wilayah ini polanya cenderung menyebar tergantung pada keberadaan sumber mata air dan ada juga yang linear searah dengan aliran kali Opak. Kali Opak yang ada di sini berfungsi sebagai pengendali banjir maupun irigasi. Untuk menjaga alur sungai maka ditetapkan daerah sepadan sungai yang luasnya di kanankiri sungai berkisar antara 50 sampai 100 meter. Di Kali Opak ini juga ada aktivitas penambangan pasir dan batu. Namun dalam penambangannya seharusnya para penambang lebih memperhatikan pola penambangannya dan harus mengendalikan aktivitas penambangan agar tidak merusak daerah alur sungai.

\section{Satuan Pegunungan Selatan}

Merupakan bentang lahan solusional dengan bahan batuan induk batu gamping, mempunyai karakteristik lapisan tanahnya dangkal dan vegetasi penutupnya relatif jarang. Bentang lahan ini terbentuk sebagai akibat proses pengangkatan dan terletak di Gunung Kidul yang dikenal sebagai Pegunungan Seribu yang merupakan perbukitan batu gamping (limestone) yang kritis, tandus dan selalu kekurangan air dengan bagian tengah terdapat dataran (Wonosari Basin).

Kawasan batu gamping yang berkembang di bagian paling selatan dari Pegunungan Selatan, khususnya di wilayah Gunungkidul, Wonogiri, dan Pacitan, berkembang menjadi topografi karst dengan sistem drainase bawah tanahnya (subterranean drainage). Sementara itu, kenampakan platonya pun pada akhirnya berubah menjadi bukitbukit kecil berbentuk kerucut (conical hillocks) yang dikenal dengan Gunung Sewu.

Di sisi selatannya, hantaman gelombang Samudera Hindia terusmenerus membentuk lereng-lereng terjal (cliff), yang di beberapa tempat diselingi oleh teluk-teluk yang sebagian terhubung dengan wilayah pedalaman melalui lembah-lembah kering. Di sisi utaranya, perbukitan kerucut Gunung Sewu berbatasan dengan dua buah ledok (basins), yaitu Ledok Wonosari di bagian barat dan Ledok Baturetno di bagian timur. Ledok Wonosari hingga kini masih mempertahankan pola drainase aslinya di aliran Sungai Oyo, yang mengalir menembus tebing-tebing tinggi di ujung barat. Ledok Baturetno di daerah Wonogiri, yang semula merupakan daerah hulu dari sebuah sungai yang mengalir ke selatan, sebagaimana ditunjukkan melalui Lembah Giritontro yang membelah Gunung Sewu ke arah Samudera Hindia, akhirnya berubah 
menjadi anak sungai bagi Bengawan Solo yang hingga saat ini mengalir ke utara.

Ledok Wonosari merupakan bagian dari wilayah karst yang kaya air karena bentukan lahannya terjadi secara deposisional, yaitu materi dari gunung api yang berupa materi piroklastik tersusun selang-seling dengan materi karst. Jenis tanah yang ada di basin ini termasuk tanah intensif yang berwarna merah dan didominasi oleh proses reduksi gleisasi yang tanahnya mempunyai kemampuan untuk melepas
$\mathrm{O}_{2}$ dan mengikat $\mathrm{H}_{2} \mathrm{O}$ dengan warna tanah yang semakin menghitam karena termasuk tanah grumusol atau margalit yang didominasi oleh materi lempung berat. Karena didominasi oleh material lempung berat maka saat musim kemarau tanahnya menjadi retak-retak yang lumayan lebar. Selain itu juga menyebabkan akar tumbuhan mudah putus karena tanahnya juga labil dan selalu kembang kempis. Sebenarnya tanah di daerah ini subur namun karena terjal maka akar sulit untuk menerima dan melepas air.

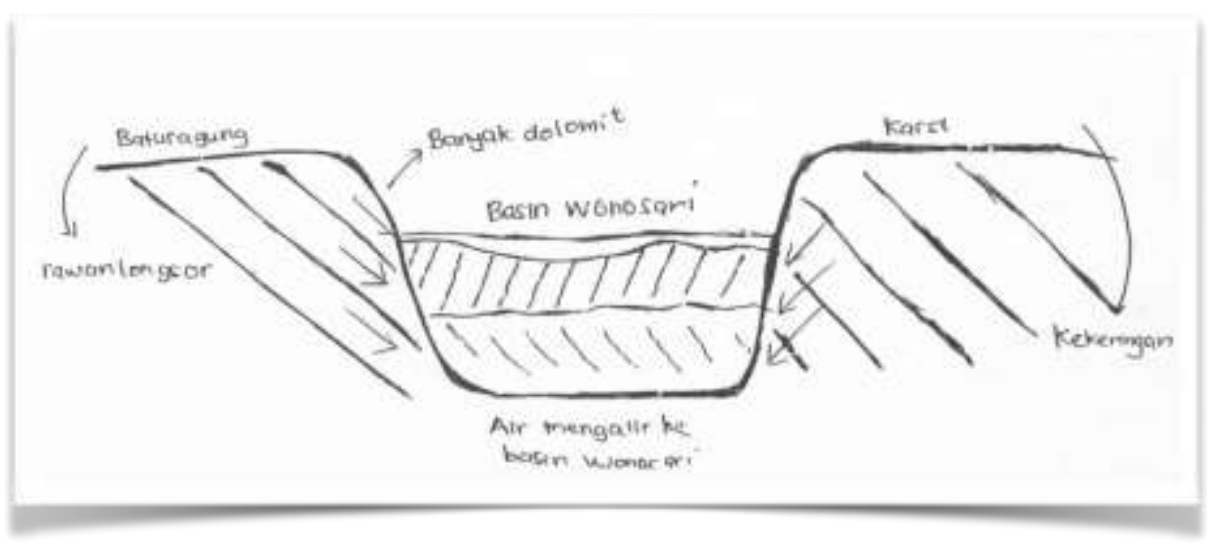

Gambar 6. Ilustrasi Basin Wonosari (Ilustrasi oleh Hidayati, 2004 \& 2018)

Penyebab kayanya akan sumber air pada basin Wonosari tak lain karena pada saat pembentukannya yaitu pada saat Perbukitan Baturagung terangkat keatas, struktur yang ada menjadi miring ke selatan. Akibatnya di struktur ini akan muncul banyak sekali retakan yang akan memicu munculnya dan mengalirnya air menuju basin yang letaknya jauh lebih rendah dan ekspresi topografinya datar.
Di sisi utara kedua ledok terdapat punggungan-punggungan tinggi dengan sisa-sisa planasinya yang tetap dipertahankan. Batas utara dari punggungan tersebut berupa tebing curam (steep escarpment), memanjang mulai daerah Parangtritis ke utara, di selatan Prambanan berbelok ke arah timur hingga Wonogiri. Di sebelah utaranya membentang dataran rendah, di mana lipatan batuan yang lebih tua turun 
cukup dalam, tertutup oleh kipas-kipas fluvio-volkanik muda dari beberapa gunung api.

Karena daerahnya ketersediaan airnya terbatas maka pola permukiman di daerah ini cenderung menyebar tergantung dengan keberadaan mata air dan doline serta di sekitar mata air tersebut pola permukimannya mengelompok. Komposisi penduduk di daerah ini didominasi oleh kelompok penduduk usia tua dan usia muda yang tidak produktif. Hal ini bisa terjadi karena banyak penduduk usia produktif yang merantau ke kota-kota besar untuk bekerja. Aspek pendapatan penduduk selain dari hasil pertanian dan tegalan, penduduk sangatlah tergantung pada remitan dari anggota keluarganya yang bekerja di luar kota.

\section{Satuan Pegunungan Kulon Progo}

Satuan Pegunungan Kulon Progo, yang terletak di Kabupaten Kulon Progo bagian utara merupakan bentang lahan struktural denudasional dengan topografi berbukit yang mempunyai kendala lereng yang curam dan potensi air tanahnya kecil. Stratigrafis yang paling tua di daerah Pegunungan Kulon Progo dikenal dengan Formasi Nanggulan, kemudian secara tidak selaras diatasnya diendapkan batuan-batuan dari Formasi Jonggaran dan Formasi Sentolo, yang menurut Van Bemmelen (1949), kedua formasi terakhir ini mempunyai umur yang sama, keduanya hanya berbeda faises. Formasi
Nanggulan merupakan formasi yang paling tua di daerah pegunungan Kulon Progo, penyusun batuan dari formasi ini menurut Raharjo (1977) terdiri dari Batupasir dengan sisipan Lignit, Napal pasiran, Batulempung dengan konkresi Limonit, sisipan Napal dan Batugamping, Batupasir dan Tuf serta kaya akan fosil foraminifera dan Moluska. Litologi dari Formasi Jonggrangan ini tersingkap baik di sekitar desa Jonggrangan, bagian bawah dari formasi ini terdiri dari Konglomerat yang ditumpangi oleh Napal tufan dan Batupasir gampingan dengan sisipan Lignit. Batuan ini semakin ke atas berubah menjadi Batugamping koral (Rahardjo, dkk, 1977). Litologi penyusun Formasi Sentolo ini di bagian bawah, terdiri dari Aglomerat dan Napal, semakin ke atas berubah menjadi Batugamping berlapis dengan fasies neritik. Batugamping koral dijumpai secara lokal, menunjukkan umur yang sama dengan formasi Jonggrangan, tetapi di beberapa tempat umur Formasi Sentolo adalah lebih muda (Purnaminingsih dan Harsono, 1981).

Pada zona ini potensi sumber daya alam terbatas. hal ini mengakibatkan banyak penduduk yang bertempat tinggal di daerah ini relatif lebih sedikit dibandingkan dengan daerah lainnya, kepadatan rendah dan persebarannya mengelompok yang berasosiasi pada ketersediaan air karena di daerah ini air 
memang sangat terbatas. Struktur penduduk di daerah ini didominasi oleh usia tua dan muda yang tidak produktif. gejala ini terjadi karena penduduk usia produktif banyak yang memilih merantau ke daerah lain untuk memperoleh pekerjaan dan penghasilan yang lebih baik. Fenomena ini menyebabkan kualitas SDM yang ada di daerah ini sangatlah rendah karena penduduk yang berpengetahuan tinggi lebih senang untuk merantau ke daerah lain yang lebih menjanjikan.

Dari segi ekonomi, penduduk di daerah ini lebih mengandalkan pada sektor pertanian lahan kering yang didominasi tegalan dan sawah tadah hujan sebagai mata pencahariannya. Selain itu di daerah ini juga dikembangkan peternakan sapi dan kambing pada saat musim penghujan karena pada saat musim kemarau ketersediaan air dan pakan sangatlah terbatas bahkan banyak peternak yang menjual ternaknya hanya untuk membeli pakan. sektor pertambangan di daerah ini juga berkembang terutama pada sektor bahan galian golongan $\mathrm{C}$.

\section{Satuan Dataran Rendah}

Satuan Dataran Rendah merupakan bentang lahan fluvial yang didominasi oleh dataran aluvial, membentang di bagian selatan Daerah Istimewa Yogyakarta mulai dari Kabupaten Kulon Progo sampai dengan Kabupaten Bantul yang berbatasan dengan Pegunungan Seribu. Wilayah ini merupakan daerah yang subur. Bentang Lahan lainnya yang belum didayagunakan secara optimal adalah bentang lahan marin dan eolin yang merupakan satuan wilayah pantai.

Karena daerah ini merupakan daerah yang subur maka daerah ini merupakan daerah lahan pertanian yang menjanjikan serta menjadi daerah tujuan pendatang. Daerah ini pada umumnya berupa kota-kota yang penduduknya sangat banyak dan padat dan pola mengelompok pada bagian kota atau daerah yang lebih datar dan pada daerah lereng pola persebarannya cenderung random. Kualitas pendidikan penduduk di daerah ini juga cukup tinggi karena lengkapnya fasilitas pendukung dan karena pendidikan telah menjadi suatu kebutuhan.

\section{KESIMPULAN}

Kondisi bentang lahan Jawa bagian tengah sisi selatan didominasi oleh batuan batugamping di bagian atas dan dialasi oleh batuan vulkanik tersier, berupa breksi dan aliran lava yang muncul di tepi laut. Kondisi ini mengakibatkan potensi sumber daya alam terbatas sehingga berpengaruh terhadap penghidupan penduduknya. Kemudian wilayah tengah hingga Gunung Merapi merupakan zona relatif lebih sempit dari bagian yang lain. Morfologi zona ini terbentuk oleh pegunungan Serayu selatan dan utara 
serta kompleks gunungapi yang relatif lebih subur dan memiliki sumber daya alam yang melimpah. Terbentuknya bentang alam tidak bisa terlepas dari unsur alam dan aktivitas manusia yang saling mempengaruhi satu sama lain.

\section{DAFTAR PUSTAKA}

Bemmelen, R. W. (1949). The geology of Indonesia (Vol. 1, No. 2). US Government Printing Office.

Bemmelen, R. W. (1970). The geology of Indonesia (Vol. 1). Martinus Nijhoff.

Bourdier, J. L., \& Abdurachman, E. (2001). Decoupling of small-volume pyroclastic flows and related hazards at Merapi volcano, Indonesia. Bulletin of Volcanology, 63(5), 309-325.

Chorley, R. J., \& Kennedy, B. A. (1971). Physical geography: a systems approach. Prentice Hall.

Conzen, M. P. (2001). Cultural landscape in geography.

Daryono, S. S. (2012). Indeks Kerentanan Seismik Berdasarkan Mikrotremor Pada Setiap Satuan Bentuklahan di Zona Graben Bantul Daerah Istimewa Yogyakarta (Doctoral dissertation, Universitas Gadjah Mada).

Deskaranti, R., Prasetyawan, I. B., \& Kunarso, K. (2017). Pemodelan Rip Current Menggunakan Model Gelombang Tipe Boussinesq (Wilayah Kajian: Pantai Klayar Jawa Timur). Journal of Oceanography, 6(1), 213-220.

Dibyosaputro, S., \& Haryono, E. (2020). Geomorfologi dasar. UGM PRESS.

Forman, R. T. (2014). Land Mosaics: The ecology of landscapes and regions (1995) (p. 217). Island Press.
Hall, R. (2009). Indonesia, geology. Encyclopedia of Islands, Univ. California Press, Berkeley, California, 454-460.

Hardjono, I. (2015). Vulkanologi dan Mineralogi Petrografi. Muhammadiyah University Press.

Hartini, S. K., \& Sartohadi, J. (2010). Morphological analysis of Merapi edifice in studying merapi-type eruption, to improve volcanic hazard map (Doctoral dissertation, [Yogyakarta]: Universitas Gadjah Mada).

Hidayat, I., Sunaryo, S., Dawwas, K. F., Rahayu, F. E., Dewanti, E. A., Handoko, E., \& Soegijono, B. (2013). OBSERVASI LINGKUNGAN: KOMPOSISI DAN STRUKTUR MATERIAL BATUAN GUNUNG MERAPI DI DI YOGYAKARTA. Jurnal Riset Sains dan Kimia Terapan, 3(2), 322-325.

Irwin, W. P. (1990). Geology and platetectonic development. The San Andreas Fault System, California, 1515, 61-80.

Islamiyah, O. R. A., Minarto, E., \& Santoso, A. B. (2019). Estimasi Kedalaman dan Perubahan Volume Sumber Tekanan Gunung Merapi Berdasarkan Pengamatan Data Tiltmeter. Jurnal Sains dan Seni ITS, 7(2), 70-74.

Kurnianto, F. A. (2019). Proses-Proses Geomorfologi pada Bentuk Lahan Lipatan. Majalah Pembelajaran Geografi, 2(2), 194-196.

Maulana, E., \& Wulan, T. R. (2015). Identifikasi agihan barkhan pada zona inti gumuk pasir Parangtritis dengan menggunakan data UAV. Simposium Nasional Sains Geoinformasi IV 2015: Penguatan Peran Sains 
Informasi Geografi dalam Mendukung Penanganan Isyu-Isyu Strategis Nasional.

Marfai, M. A., Cahyadi, A., \& Anggraini, D. F. (2013). Tipologi, Dinamika, dan Potensi Bencana Di Pesisir Kawasan Karst Kabupaten Gunungkidul.

Mitchell, D. (2002). Cultural landscapes: the dialectical landscape-recent landscape research in human geography. Progress in human geography, 26(3), 381-389.

Mulyasari, R., Brahmantyo, B., \& Supartoyo, S. (2020). ANALISIS KUANTITATIF AKTIVITAS TEKTONIK $\mathrm{R}$ ELATIF DI PEGUNUNGAN BATURAGUNG JAWA TENGAH. Bulletin of Geology, 1(1), 40-53.

Muryowihardjo, S. (1988). Jenis Erupsi Gunungapi yang Menghasilkan Batuan Volkanik di Daerah Gunung Baturagung Kabupaten Gunungkidul Yogyakarta.

Nossin, J. J., \& Voute, C. (1986). Notes on the geomorphology of the Borobudur plain (Central Java, Indonesia) in an archaeological and historical context. In Remote sensing for ressources development and environmental management. International symposium. 7 (pp. 857 864).

Nurkholis, A., Jayanto, G. D., \& Jurnawan, N. Y. (2018). ANALISIS BENTUKLAHAN SEBAGAI LANDASAN TERWUJUDNYA SUSTAINABLE COASTAL AREA DI INDONESIA.

Pannekoek, A. J. (1949). Outline of the geomorphology of Java.

Purnamaningsih, S., \& Harsono, P. (1981). Stratigraphy and planktonic foraminifera of the Eocene-Oligocene
Nanggulan Formation, central Java. Publ Geol Res Devel Centre Paleont Series, 1, 9-28.

Rayes, M. L. (2017). Morfologi dan Klasifikasi Tanah. Universitas Brawijaya Press.

RETNOWATI, A. (2011). Rip currents signatures zone detection on alos palsar image at Parangtritis Beach (Doctoral dissertation, [Yogyakarta]: Universitas Gadjah Mada).

Rowntree, L. B. (1996). The cultural landscape concept in American human geography. Concepts in human geography, 70(4), 459-474.

Rudiyanto, A. (2017). SISTEM INFORMASI GEOGRAFIS PERTANIAN PADI DI KABUPATEN BANTUL, DI YOGYAKARTA. SELODANG MAYANG, 3(1).

Sarkowi, M. (2010). Interpretasi Struktur Bawah Permukaan Daerah Gunung Merbabu-Merapi Berdasarkan Pemodelan 3d Anomali Bouguer. BERKALA FISIKA, 13(2), 11-18.

Santosa, L. W. (2006). Geomorphological approach for regional zoning in the Merapi volcanic area. Indonesian Journal of Geography, 38(1).

Santosa, L. W. (2016). Keistimewaan Yogyakarta dari sudut pandang geomorfologi. UGM PRESS.

Setiahadiwibowo, A. P., Nugroho, O. B., \& Pratama, Y. A. (2020). Penentuan Nilai Resistivitas Unconsolidate Sand pada Low Moisture Content Menggunakan Mikroamperemeter pada Aliran Sungai Krasak Sleman, Daerah Istimewa Yogyakarta. JURNAL GEOCELEBES, 4(1), 46-52.

Setyawan, M. A., Apriyanto, B., \& Astutik, S. (2019). ANALISIS 
KARAKTERISTIK ENDAPAN MARINE DAN PENGARUHNYA BAGI SEKTOR PERTANIAN DAN PERAIRAN DI PESISIR SELATAN PANTAI PANCER KECAMATAN PUGER KABUPATEN JEMBER JAWA TIMUR. MAJALAH PEMBELAJARAN GEOGRAFI, 2(1), 141-154.

Strahler (1987). Modern Physical Geography.New York : John Willey $\&$ Sons.

Suyanto, I. (2012). Pemodelan Bawah Permukaan Gunung Merapi Dari Analisis Data Magnetik Dengan Menggunakan Software Geosoft. Laporan Penelitian.

Thouret, J. C. (1999). Volcanic geomorphology - an overview. Earth-science reviews, 47(1-2), 95131.

Thouret, J. C., Lavigne, F., Kelfoun, K., $\&$ Bronto, S. (2000). Toward a revised hazard assessment at Merapi volcano, Central Java. Journal of Volcanology and Geothermal Research, 100(1-4), 479-502.

Tjia, H. D. (1961). Aerial Observation of Gunung Merapi Central Djava. Journal of Mathematical and Fundamental Sciences, 1(4), 2-7.

Turner, M. G. (1989). Landscape ecology: the effect of pattern on process. Annual review of ecology and systematics, 20(1), 171-197.

Tuttle, S. D. (1975). Landforms and landscapes (No. 04; GB401, T8 1975.).

Verstappen, H. T. (1957). Short note on the dunes near Parangtritis (Java).

Verstappen, H. T. (1983). Applied geomorphology. Elsevier Science
Publishing Co., New York, N.Y. 437pp

Verstappen, H. T. (1988).

Geomorphological surveys and natural hazard zoning, with special reference to volcanic hazards in central Java. Zeitschrift für Geomorphologie. Supplementband, 68, 81-101.

Verstappen, H. T. (2000). Outline of the Geomorphology of Indonesia: A Case Study on Tropical Geomorphology of a Techtogene Region. ITC Publication, (79).

Verstappen, H. T. (2011). Old and new trends in geomorphological and landform mapping. In Developments in earth surface processes (Vol. 15, pp. 13-38). Elsevier.

Voight, B., Constantine, E. K., Siswowidjoyo, S., \& Torley, R. (2000). Historical eruptions of Merapi volcano, central Java, Indonesia, 1768-1998. Journal of Volcanology and Geothermal Research, 100(1-4), 69-138.

Wardhana, P. N. (2015). Analisis transpor sedimen Sungai Opak dengan menggunakan program HECRAS 4.1. 0. Jurnal Teknisia, 20(1), 22-31.

Wessel, P., \& Kroenke, L. W. (2000). Ontong Java Plateau and late Neogene changes in Pacific plate motion. Journal of Geophysical Research: Solid Earth, 105(B12), dd2825528277.

Wismaya, Y. G. (2016). Pemodelan Deformasi Gunung Merapi Dengan Model Yokoyama Menggunakan Data GPS (Doctoral dissertation, Institut Teknologi Sepuluh Nopember). 